\title{
Top Stressors among Filipino Undergraduate Students: A Multicenter - Interdisciplinary Study
}

\author{
Glynne P. Bate, Marivel B. Go, and Severina P. Velos \\ Cebu Technological University - Moalboal Campus \\ glyn_pbate@yahoo.com
}

\section{Abstract}

Stress has been identified as the antecedent for undesirable outcomes, such as depression and self-harm but there still lack of awareness on extent of its impact on academics most notably in a developing country like the Philippines. Thus, a multicenter and interdisciplinary study was employed on 501 students from six state universities in the Philippines. A questionnaire structured to assess the perception of the students as to the severity of identified stressors) as well as the prevalence of the coping mechanisms they adopt to overcome stress was used. The results indicated that academic stressors proved to be the main contributory factor to levels of distress among undergraduates. Educators and decision-makers should tailor regular student evaluations and programs that ensure the impediment of the sources of stress and other measures for further prevention.

Keywords: stress, mental health, stressors, coping mechanisms, undergraduate students, university students

\subsection{Introduction}

Educators primarily view stress as a common and recurrent phenomenon in the educational discourse of university students (Chernomas \& Shapiro, 2013). It poses a real challenge to achieve the desired outcome. By definition, stress is a state when external demands exceed one's resources resulting in degrading effects on emotional, behavioral, mental, and physiological levels (Dickerson \& Kemeny, 2004). In essence, it is the innate response the human body manifests as it goes through pressures from situations or life events. Different circumstances lead to varying degrees of perceived stress levels. In an academic context, specifically among undergraduate students, some of the leading stressors are deadlines, peer pressure, and the demand to succeed (Beiter et al., 2015). Lack of concern and little awareness of how stress obtrudes concentration, problem-solving, comprehension (Uehara, Takeuchi, Kubota, Oshima, \& Ishikawa, 2010), and memory function (Aggarwal, Wilson, \& Beck, 2014) among other fundamental attributes of learning by most universities stunts every student's holistic development. Academics may be an integral element of student life (Beiter et al., 2015) but in the absence of a healthy attitude towards the achievement and goals, stress, though perceived to be a positive reinforcement in learning capacity and competency development (Kumaraswamy, 2013), can corrupt intellectual performance (Beiter et al., 
2015) leading to detrimental outcomes to mental health and well-being (Kumaraswamy, 2013). Stress has also led to relationship struggles (Ali, Rahbar, Naeem, Tareen, Gui, \& Samad, 2002) and difficulty with job acquisition (Eisenberg, Golberstein, Gollust, \& Hefner, 2007).

In another perspective, stress as a response is a normal biological and psychological human attribute (Mahar, Bambico, Mechawar, \& Nobrega, 2014). When individuals come across stressinducing activities and life events, the human body is stimulated by the brain to induce hormones that stimulate the so-called 'fight' or 'flight' response. (Segerstrom \& Miller, 2004). This two-way physiological feedback then affects how the individual perceives stress as either positive or negative impression. However, intermittent exposure to stress, especially in cases where the source cannot be subjugated, yields to experiencing issues in mental health (i.e., anxiety and depression) inevitable (Lupien, McEwen, Gunnar, \& Heim, 2009; Mahar et al., 2014). According to a national research survey conducted by American College Health Association (2018), in the United States of America (USA) alone, over $17 \%$ of college students reported having leading episodes of depression. Meanwhile, about 165 million people in Europe are affected by mental disorders (Trautmann, Rehm, \& Wittchen, 2016). Such high rates of reported mental health issues prove to be alarming since they often lead to various societal problems (Song \& Lindquist, 2015). According to the Organization for Economic Cooperation and Development (2019), the burden of mental disorders in the economy comprises about $4 \%$ of a nation's Gross Domestic Product (GDP). In detail, globally accounting for the direct and indirect costs of mental disorders, the numbers were approximately US $\$ 0.8$ trillion and US $\$ 1.7$ trillion, respectively (Gustavsson, Svensson, Jacobi, Allgulander, Alonso, Beghi... Fratiglioni, 2010). Such high numbers pose as a warning to influential personage to start taking interceptive measures. Moreover, depression, when left untreated has also been known to lead to self-harm (Wu, Rockett, Yang, Feng, Jiang, \& Yu, 2016) and even suicide (Song \& Lindquist, 2015), with the latter being the second major global death cause among the youth who are between the ages of 15-29 years old (World Health Organization, 2017). In the Philippines, people who suffered depressive disorders account for about $3.3 \%$ of the total Filipino population in 2012. And 1 out of its 17 regions reported having 108 suicide cases from January to August 2018 alone (ParrochaDilim, 2018), all pointing to the rudimentary behavior of a developing country (Divaris, Barlow, Chendea, Cheong, Dounis, Dragan, \& ... Mo'nes, 2008). And though alarming, only a few studies have been conducted focusing on stress among students in developing and middle-income countries (Supe, 1998; Saipanish, 2003; Shaikh, Kahloon, Kazmi, Khalid, Nawaz, Khan, \& Khan, 2004; Sherina, Rampal, \& Kaneson, 2004; Hetolang \& Amone-P'Olak, 2018). The dramatic consequences of stress-induced suicide are not limited to the affected families. It also becomes a traumatic experience for teachers (Kõlves, Ross, Hawgood, Spence, \& De Leo, 2017) and the college or university. Furthermore, these incidents can be easily broadcasted on social media and eventually gain a national reach, which can easily ruin the school's image and reputation. Thus, recognizing the need to understand the sources of psychological distress and the efficient response to handling them is a necessary undertaking for educators and universities. Awareness of manifestations of stress and its associated mental ill-effects will help the academic community plan 
programs and interventions and effectively oversee its implementation (Chernomas \& Shapiro, 2013).

Stress and its associated mental disorders among university students are widely discussed in the current literature. The study by Beiter et al. (2015) investigated the probable factors in correlation with increased frequency of visits to counseling centers due to anxiety, stress, and depression in a sample among tertiary level students. Results indicated that the pressure to succeed, academic performance, and plans after graduation were the main contributors to stress-induced mental health issues. These proved to be consistent with the results of Liu et al. (2019), where one predictor of depressive symptoms was stressful life events. Other studies have also dealt with how stress leads to sickness absence, self-harm, suicide attempts, and, when left ignored, suicide (Gémes et al., 2019; Wu et al., 2016; Tang, Byrne, \& Qin, 2018). Moreover, the extension developed by Lee, K., Lee, H.K., and Kim (2017) led to a disclosure on the relationship between different personality dimensions and suicidal behaviors. Other extensions also included analysis between societal cohorts. Wyatt and Oswalt (2013) studied graduate and undergraduate students and the difference between their experiences on issues of mental health. The latter reported having experienced stress at a significantly higher level. Though a vast majority is devoted to studying the stress-induced mental ill-health of undergraduate medical students, it is not necessarily limited. Studies by Denovan and Macaskill (2017) and Zimmaro et al. (2016) studied the effects of stress on the well-being and mental health of undergraduates studying psychology. Others studied with a more interdisciplinary approach focusing on thorough discussions and analysis of stress and its ill effects on school performance, relationships, and mental well-being regardless of demographic profile, and program, among other academic cohorts. Previous studies have also investigated the difference in stress levels among different undergraduate programs/departments. For example, the study of Elias, Ping, and Abdullah (2011) assessed the stress levels of undergraduate students enrolled in fifteen (15) degree programs in one university in Malaysia. Findings revealed a significant difference in the stress levels of students with different degree programs. Similar results have also been previously obtained by Abouserie (1994), who conducted a study on 675 second-year undergraduate students from nine departments at the University of Wales College of Cardiff.

In addition, several works have also focused on the formation and assessment of plausible solutions to stress reduction such as interventions and programs (Saeed, Bahnassy, Al-Hamdan, \& Almudhaibery, 2016; van der Riet, Rossiter, Kirby, Dluzewska, \& Harmon, 2015; Hindman, Binder, Moltu \& Dundas, 2015; Hjeltnes, Binder, Moltu, \& Dundas, 2015; Dariotis et al., 2016). However, there has yet to be a study with a multicenter and interdisciplinary approach far-reaching data from and between universities and undergraduate programs in developing countries along with an analysis as to the various stressors associated with student life and the necessary measures to adapt to overcome stress.

Hence, the goal of the current study is to evaluate the extent different stressors contribute to undergraduate student distress and other involved interrelationships thereof. Also, the study further examines the similarity or difference between students' perceived stress under various undergraduate programs and their significance and copingmechanismstostress. The contributoryfactors 
to stress may be grouped into four: (1) academic stressors, (2) social stressors, (3) emotional stressors, and (4) financial stressors (Pariat, Rynjah, Joplin, \& Kharjana, 2014). In particular, student competition, family expectation, excessive work or course load, and expectations of teachers are identified to be academic stressors. Relatively, the gauge on the stress level perceived by undergraduate students are due to factors that affect academic ability and performance. The social stressors spring from social events like, trouble getting along with others, peer pressure, and being friendless. An interpersonal outlook on the attributes of stress helps shape a holistic approach to assessment and intervention. Emotional stressors pertain to contributory factors to stress brought about by intrapersonal experiences and struggles. These are romantic relationships adjustment and management, no control of how things are going, lack of confidence in oneself, and absence of someone to rely on. The last group is on financial stressors pertain primarily to monetary funds and resources, particularly, the lack thereof. This includes absence of money assistance from the family, monetary expenditures controlled by parents, budget management problems, and lack of financial resources to pay for school projects and other school expenses. Being able to identify the primary source of stress among undergraduate students will help educators and universities identify and consequently implement courses of action to intercept and address issues in the long run to prevent future occurrences.

The study provides more information to the existing body of literature on the mental health of university students in two ways. One, it provides a multicenter and interdisciplinary approach to the analysis of stress levels and its sources along with an assessment of the adopted stress coping mechanisms in the context of students within developing countries. Two, the results contribute insights on policy development of plausible interventions by teachers and universities to reduce and prevent the incidence of stress-related mental health issues together with the implications of developing an effective program for support services and counseling. Such endeavors prove to be crucial to ensuring a healthy learning environment. This paper is prepared as follows: In section 2, a discussion on the methods and data gathering instruments. Section 3 describes the obtained results from the treatment of the data, and Section 4 gives a conclusion and considerable directions for future work.

\subsection{Methodology}

This study employed a descriptive research design with survey method to describe the stress level of the undergraduate students in different programs and universities. They were randomly selected from six state universities in Cebu City, Philippines. The determination of the participants was done after permission was granted to look into the list of enrolled students from the instructors in each of the different undergraduate programs and all even numbers in the list were chosen as the participants of the study. About 501 students agreed to participate of which, males composed $36.9 \%(\mathrm{~N}=185)$ and females composed $60.9 \%$ $(\mathrm{N}=305)$ while $2.2 \%$ chose gender discretion ( $\mathrm{N}$ $=11)$. The respondents were between the ages of 16-24 years old, most of whom were between 19-21 years old (56\%). Regarding the density of undergraduate programs, $18.4 \%$ were studying Elementary and Secondary Education, 28.3\% had majored in Engineering, 12.4\% were students 
from the College of Arts and Sciences, 22.8\% were from the Technology department, and $18.2 \%$ were Agriculture majors. The researchers obtained ethical approval from each university's campus directors before the gathering of the data. The modified questionnaire was adopted from the study of Pariat et al. (2014) as the main instrument in the analysis of the relationships between programs, and the coping mechanisms. The items reflected in the questionnaire were chosen as they have good discrimination value based on the method of item analysis by Davis (1946). It also has a construct validity of 0.72 , which was established with the use of a test developed in India. While reliability was established in two forms. The coefficient alpha of 0.78 , significant at the 0.01 significance level, determined the internal consistency of the questionnaire. Its stability over time was done through the test-retest and resulted to a 0.71 reliability.

The questionnaire included three sections. The modification is employed in the first section of the questionnaire that contains the respondents' demographic information. Changes were made to fit into the type of respondents for this study. It included a requirement for the participants to supply their degree program. The next section contains a group of contributory factors to stress to which highlighted four stressors, namely, academic, emotional, social, and financial stressors, with each elaborated with specifics. The last section included a list of items describing strategies for coping with stress, which included notions on positive and negative coping mechanisms.

The respondents were asked to determine the degree to which each particular stressor contributed to their level of stress. The 4-point Likert scale was used to score each item ( $1=$ did not contribute, 2 = slightly contributed, $3=$ contributed, and $4=$ greatly contributed), which served as a measure of severity rather than as a diagnostic test. As to the stress coping mechanisms, each item was given a rating as to the prevalence of its suitability in dealing with distinct stressful student life events. On the same note, it employed another set of a 4-point Likert scale ( 4 = always, $3=$ often, $2=$ sometimes, $1=$ never). The licensed IBM Statistical Package for the Social Sciences (SPSS) software version 25.0 was utilized to carry out the data analysis. Missing values and other illogical data were extracted and removed after thorough data cleaning. The stressors treated as the outcome variables were presented as weighted means. To test for differences in the stress levels among the four categories of stressors and, by undergraduate program, the one-way Analysis of Variance (ANOVA) was used that yielded to be significant at $p<0.05$. To ensure that no violation was made to the assumptions of normality and linearity, a preliminary analysis was conducted before the engagement of data treatment.

\subsection{Results and Discussion \\ Contributory Factors to Stress}

Upon data treatment, it can be seen in Figure 1 that among the four contributory factors to stress, academic stressors have the highest weighted mean score by all undergraduate programs. It is followed by financial and emotional both coming close with near similar results, while social stressors prove to be the least perceived as the cause of distress among undergraduate students. Statistical analysis further justifies the results garnered from the weighted mean (see Table 1). Statistically significant relationships were found primarily from two groups. A statistically significant relationship towards the stress level experienced by undergraduate students 
existed for the academic $(F(4,495)=9.835, p=0.000)$ as well as financial $(F(4,495)=6.165, p=0.000)$ stressors. However, social $(F(4,495)=0.489, p=$ $0.744)$ and emotional $(F(4,495)=2.326, p=0.055)$ stressors proved to be statistically insignificant. This exhibits analogous results with the study of Sohail (2013), Melaku, Mossie, and Negash (2015), and Bedewy and Gabriel (2015), where students in developing countries experienced higher associations of distress due to academic stressors (i.e., student competition, family expectation, excessive work or course load, and expectation of teachers). Pressures resulting from high academic expectations from family, faculty and peers have long been associated as the main source of stress among students (Sarita, 2015). The results, however recurrent, prove that the majority of the academic community continues to view this as rudimentary and ceases to take preventive measures. Stress may be considered as a humdrum within the academic context. However, it does not undermine the fact that strong conjectures prove a change in the approach of learning or even implementing supplementary materials and programs to assist in the liberation of the undergraduate students from their stress-induced academic struggles. For instance, state universities may consider indoctrinating a strong role in guidance counselors for consultation and mentorship, which, in turn, would encourage students to seek professional advice rather than taking matters into their own hands. Another notion is to have regular programs and seminars on mental health incorporated in the modules of undergraduate students.

On another note, the results from Lim, Heckman,
Montalto, and Letkiewicz (2014), Heckman, Lim, and Montalto (2014), and Britt, Mendiola, Schink, Tibbetts, and Jones (2016), financial stressors were concluded to be among those highly associated with high-stress levels. Such an outcome may have slightly varied with the findings from the current study. In the Philippine perspective, majority of undergraduate students were exposed to episodes of difficulty and poverty (Mina \& Imai, 2017; Figueroa, Lim, \& Lee, 2018) that they have become accustomed to recurring occasions of financial instability. As such, Philippine undergraduate students may view this minor threat compared to academics, and thus placed as the second-highest contributor to stress. Finances are primarily established more of as a general economic quagmire shared by the majority of Filipinos, whereas academics are sought to be more innate. As to the emotional and social stressors, results from the one-way ANOVA suggest that the difference can be more attributed to the high variation in the responses from the students rather than between stressors. As such, the perceived level of distress caused by these two stressors varies from person to person. For instance, a highly friendly, outgoing individual would find social stressors more of a positive engagement rather than a source of mental weight. These individuals prefer to have more interactions with others, to which they also find as a way to alleviate themselves from feelings of tension and dread. Moreover, people with higher emotional intelligence can cope more efficiently with physical and mental pressures from life events and thus, tend to have lower levels of perceived distress. This conforms to the study of Urquijo, Extremera, and Villa (2016). 


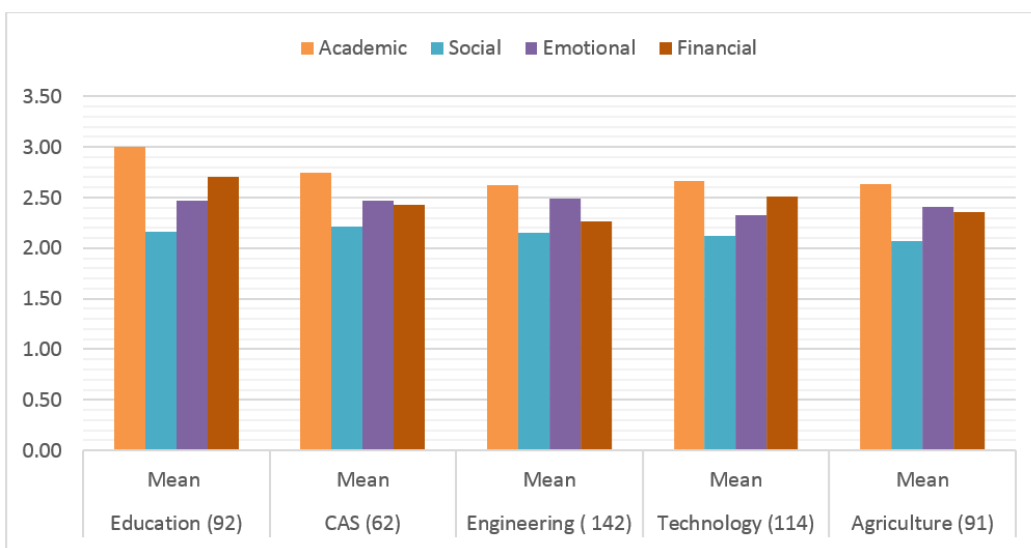

Figure 1. Contributory Factors to Stress by Course and their Weighted Means

Table 1. The Four Contributory Factors to Stress and their One-Way ANOVA Results

\begin{tabular}{llccccc}
\hline & & $\begin{array}{c}\text { Sum of } \\
\text { Squares }\end{array}$ & df & $\begin{array}{c}\text { Mean } \\
\text { Square }\end{array}$ & F & Sig. \\
\hline \multirow{2}{*}{ Academic } & Between Groups & 10.200 & 4 & 2.550 & 9.835 & .000 \\
Stressors & Within Groups & 128.344 & 495 & .259 & & \\
& Total & 138.543 & 499 & & & \\
\hline \multirow{2}{*}{ Social } & Between Groups & .769 & 4 & .192 & 0.489 & .744 \\
Stressors & Within Groups & 194.458 & 495 & .393 & & \\
& Total & 195.227 & 499 & & & \\
\hline \multirow{2}{*}{$\begin{array}{l}\text { Emotional } \\
\text { Stressors }\end{array}$} & Between Groups & 4.139 & 4 & 1.035 & 2.326 & .055 \\
& Within Groups & 220.192 & 495 & .445 & & \\
& Total & 224.331 & 499 & & & \\
Financial & Between Groups & 12.260 & 4 & 3.065 & 6.165 & .000 \\
Stressors & Within Groups & 246.088 & 495 & .497 & & \\
& Total & 258.347 & 499 & & & \\
\hline
\end{tabular}

Students' Stress Levels in Different Undergraduate

\section{Courses}

The one-way ANOVA test results presented in Table 2 show that the undergraduate programs resulted in a $p$-value $(p=0.075)$ greater than 0.05 . It identifies a statistically insignificant difference in stress scores between students in different academic cohorts. This is in contradiction to the study of Larcombe et al. (2016), where diverse programs resulted in a disparity in the perceived stress level. $A$ group of Australian students from different academic fields of study was the focus of the study. The 
plausible reasons for the varied perceptions in stress level between courses can be attributed to specific differences in curriculum, the instructor's qualification, level of expertise, and teaching methods, and, to some extent, the level of consideration towards the students' well-being (Melaku et al., 2015).

As such, the results in this paper may have reflected the inherent trait of the Filipinos to be primarily an optimistic nationality that, regardless of the different sources of stressors and experiential differences between courses, stress proves to be invariable. For instance, even in the advent of highly stressful events such as natural calamities and disasters, Filipinos tend to continue to have a positive attitude, which assists in their expedited recovery during the aftermath of the disaster (Balgos, 2014). In smaller stressful cases such as the pressures in the academe, it proves to be a challenge that can be easily overcome.

Table 2. Undergraduate courses and their relationship between stress levels.

\begin{tabular}{lccccc}
\hline Source of Variation & $\begin{array}{c}\text { Sum of } \\
\text { Squares }\end{array}$ & df & Variance & F & p \\
\hline Between Groups & 3.07 & 4 & 0.768 & 2.142 & 0.075 \\
Within Groups & 177.781 & 496 & 0.358 & & \\
Total & 180.852 & 500 & & & \\
\hline
\end{tabular}

\section{Coping Mechanisms to Stress}

The result in this paper further indicates that undergraduate students from these state universities tend to adopt positive coping mechanisms rather than the negative. The most adopted coping mechanism was carrying out constructive distractions in the form of activities or social interactions to cultivate happy thoughts and emotions. Though negative coping mechanisms (e.g., smoking, alcohol, and drugs) are inevitable (Bravo, Pearson, Stevens \& Henson, 2016), they are less likely used. Thus, universities should be guided that in the conception of programs and extensions, specific approaches per undergraduate program is necessary to achieve an active brigade towards a student's development in an environment that promotes mental health.

Conclusively, it may be said that various factors interplay in the stress experienced by undergraduate students in developing countries. And as such, these call for the attention and immediate course of action of the academic community in establishing programs specifically targeted for the betterment of the mental health and stability of the students. Also, the results above prove to be vital pieces of information in the design and development of the interventions. One, universities are encouraged to focus primarily on academic stressors as these significantly contribute to stress and its associated mental health issues. Two, in a more focused point of view, there is a necessity for specific colleges and departments to devise curricula and services tailored to suit the needs of the students in varying academic fields of study. And three, due to an individual's inherent trait of being unique, it may be necessary to conduct tests as to what coping mechanisms in particular best correspond to the needs of the students and what may be done to 
enhance their capabilities of restoration and healing. Decision-makers in the academic community are guided in their policy-making strategies so they become equipped to take action before problems become chronic and irreversible

\subsection{Conclusion}

The present results show the association between stressors and other factors within different undergraduate courses, and the various coping mechanisms in a developing country perspective, particularly, in the Filipino populace. However, there are certain limitations to consider in the interpretation of the results. One, results may be different for private universities since their structure, culture, and educational platforms differ from that of state universities. As such, they may not reflect the general perspective on the matter so that future research is recommended to determine the variations between private and state universities in developing countries. Two, the consideration of age, gender, religious beliefs, state of living, family background, and history, among other aspects, may give a more in-depth insight as to their effects on stress level perception.

\section{References}

Abouserie, R. (1994). Sources and levels of stress in relation to locus of control and self esteem in university students. Educational psychology, 14(3), 323-330.

Aggarwal, N. T., Wilson, R. S., Beck, T. L., Rajan, K. B., De Leon, C. F. M., Evans, D. A., \& Everson-Rose, S. A. (2014). Perceived stress and change in cognitive function among adults aged 65 and older. Psychosomatic medicine, 76(1), 80.
Ali, B., Rahbar, M., Naeem, S., Tareen, A., Gui, A., \& Samad, L. (2002). Prevalence of and factors associated with anxiety and depression among lower middle class semi-urban community of Karachi, Pakistan. Journal of the Pakistan Medical Association, 52, 513517.

American College Health Association (2018). American College Health Association National College Health Assessment II: Reference group executive summary Fall 2018. Silver Spring, MD. Retrieved from: https://www.acha.org/documents/ncha/ NCHAll_Fall_2018_Reference_Group_Executive_ Summary.pdf

Balgos, B. C. (2014). People's response to disasters: vulnerability, capacities, and resilience in Philippine context. Philippine Political Science Journal, 127-129.

Bamuhair, S. S., Al Farhan, A. I., Althubaiti, A., Agha, S., \& Ibrahim, N. O. (2015). Sources of stress and coping strategies among undergraduate medical students enrolled in a problem-based learning curriculum. Journal of Biomedical Education, 2015.

Bedewy, D., \& Gabriel, A. (2015). Examining perceptions of academic stress and its sources among university students: The Perception of Academic Stress Scale. Health psychology open, 2(2), 2055102915596714.

Beiter, R., Nash, R., McCrady, M., Rhoades, D., Linscomb, M., Clarahan, M., \& Sammut, S. (2015). The prevalence and correlates of depression, anxiety, and stress in a sample of college students. Journal of affective disorders, 173, 90-96. 
Bravo, A. J., Pearson, M. R., Stevens, L. E., \& Henson, J. M. (2016). Depressive symptoms and alcohol-related problems among college students: a moderatedmediated model of mindfulness and drinking to cope. Journal of studies on alcohol and drugs, 77(4), 661-666.

Britt, S. L., Mendiola, M. R., Schink, G. H., Tibbetts, R. H., \& Jones, S. H. (2016). Financial stress, coping strategy, and academic achievement of college students. Journal of Financial Counseling and Planning, 27(2), 172-183.

Chernomas, W. M., \& Shapiro, C. (2013). Stress, depression, and anxiety among undergraduate nursing students. International journal of nursing education scholarship, 10(1), 255-266.

Dariotis, J. K., Cluxton-Keller, F., Mirabal-Beltran, R., Gould, L. F., Greenberg, M. T., \& Mendelson, T. (2016). "The program affects me'cause it gives away stress": Urban students' qualitative perspectives on stress and a school-based mindful yoga intervention. Explore, 12(6), 443-450.

Davis, F.B. (1946). Item-analysis data; their computation, interpretation, and use in test construction. Harvard Education Papers.

Denovan, A., \&Macaskill, A. (2017). Stress and subjective well-being among first year UK undergraduate students. Journal of Happiness Studies, 18(2), 505525.

Dickerson, S. S., \& Kemeny, M. E. (2004). Acute stressors and cortisol responses: A theoretical integration and synthesis of laboratory research. Psychological Bulletin, 130, 355-391.
Divaris, K., Barlow, P. J., Chendea, S. A., Cheong, W. S., Dounis, A., Dragan, I. F., \& ... Mo'nes, M. (2008). The academic environment: the students' perspective. European Journal of Dental Education, 12, 120-130.

Eisenberg, D., Golberstein, E., Gollust, S., \& Hefner, J. (2007). Prevalence and correlates of depression, anxiety and suicidality among university students. American Journal of Orthopsychiatry, 77, 534-542.

Elias, H., Ping, W. S., \& Abdullah, M. C. (2011). Stress and academic achievement among undergraduate students in Universiti Putra Malaysia. ProcediaSocial and Behavioral Sciences, 29, 646-655.

Figueroa, L. L., Lim, S., \& Lee, J. (2018). Modelling the effect of deprived physical urban environments on academic performance in the Philippines. GeoJournal, 83(1), 13-30.

Gémes, K., Frumento, P., Almondo, G., Bottai, M., Holm, J., Alexanderson, K., \& Friberg, E. (2019). A prediction model for duration of sickness absence due to stress-related disorders. Journal of affective disorders, 250, 9-15.

Gunasingam, N., Burns, K., Edwards, J., Dinh, M., \& Walton, M. (2015). Reducing stress and burnout in junior doctors: the impact of debriefing sessions. Postgraduate medical journal, 91(1074), 182-187.

Gustavsson, A., Svensson, M., Jacobi, F., Allgulander, C., Alonso, J., Beghi, E.., Fratiglioni, L. (2010). Cost of disorders of the brain in Europe. European Neuropsychopharmacology, 21: 718-779.

Heckman, S., Lim, H., \& Montalto, C. (2014). Factors related to financial stress among college students. 
Journal of Financial Therapy, 5(1), 3.

Hetolang, L. T., \& Amone-P'Olak, K. (2018). The associations between stressful life events and depression among students in a university in Botswana. South African Journal of Psychology, 48(2), 255-267.

Hindman, R. K., Glass, C. R., Arnkoff, D. B., \& Maron, D. D. (2015). A comparison of formal and informal mindfulness programs for stress reduction in university students. Mindfulness, 6(4), 873-884.

Hjeltnes, A., Binder, P. E., Moltu, C., \& Dundas, I. (2015). Facing the fear of failure: An explorative qualitative study of client experiences in a mindfulness-based stress reduction program for university students with academic evaluation anxiety. International journal of qualitative studies on health and wellbeing, 10(1), 27990.

Kõlves, K., Ross, V., Hawgood, J., Spence, S. H., \& De Leo, D. (2017). The impact of a student's suicide: Teachers' perspectives. Journal of affective disorders, 207, 276281.

Kumaraswamy, N. (2013). Academic stress, anxiety and depression among college students - a brief review. International Review of Social Sciences and Humanities, 5(1), 135-143.

Larcombe, W., Finch, S., Sore, R., Murray, C. M., Kentish, S., Mulder, R. A., \& ... Williams, D. A. (2016). Prevalence and socio-demographic correlates of psychological distress among students at an Australian university. Studies in Higher Education, 41(6), 1074-1091.
Lee, K., Lee, H. K., \& Kim, S. H. (2017). Temperament and character profile of college students who have suicidal ideas or have attempted suicide. Journal of affective disorders, 221, 198-204.

Lim, H., Heckman, S., Montalto, C. P., \& Letkiewicz, J. (2014). Financial stress, self-efficacy, and financial help-seeking behavior of college students. Journal of Financial Counseling and Planning, 25(2), 148-160.

Liu, Y., Zhang, N., Bao, G., Huang, Y., Ji, B., W. Y., \& ... Li, G. (2019). Predictors of depressive symptoms in college students: A systematic review and metaanalysis of cohort studies. Journal of affective disorders, 244, 196-208.

Lupien, S., McEwen, B., Gunnar, M., \& Heim, C. (2009). Effects of stress throughout the lifespan on the brain, behavior and congnition. Nature Reviews. Neuroscience, 10, 434-445.

Mahar, I., Bambico, F. R., Mechawar, N., \& Nobrega, J. (2014). Stress, serotonin, and hippocampal neurogenesis in relation to depression and antidepressant effects. Neuroscience and Biobehavioral Reviews, 38, 173-192.

Melaku, L., Mossie, A., \& Negash, A. (2015). tress among medical students and its association with substance use and academic performance. Journal of Biomedical Education, 2015.

Mina, C.D., \&Imai, K. S. (2017). Estimation of vulnerability to poverty using a multilevel longitudinal model: Evidence from the Philippines. The Journal of Development Studies, 53(12), 2118-2144. 
Organization for Economic Co-operation and Development (2019). Mental Health. Retrieved from:http://www.oecd.org/health/health-systems/ mental-health.htm

Pariat, L., Rynjah, M., Joplin, M., \& Kharjana, M. (2014). Stress levels of college students: interrelationship between stressors and coping strategies. IOSR J. Humanit. Soc. Sci, 19, 40-45.

Parrocha-Dilim, Joanne Namnama (2018). Suicide can be prevented, DOH-1 officials say. Republic of the Philippines:PhilippineInformationAgency. Retrieved from: https://pia.gov.ph/news/articles/1012558

Saeed, A. A., Bahnassy, A. A., Al-Hamdan, N. A., Almudhaibery, F. S., \& Alyahya, A. Z. (2016). Perceived stress and associated factors among medical students. Journal of family \& community medicine, 23(3), 166.

Saipanish, R. (2003). Stress among medical students in a Thai medical school. Medical teacher, 25(5), 502506.

Sarita, S. (2015). Academic stress among students: role and responsibilities of parents. International Journal of Applied Research, 1(10), 385-388.

Segerstrom, S., \& Miller, G. (2004). Psychological stress and the human immune system: A meta-analytic study of 30 years of inquiry. Psychological Bulletin, $130,601-630$.

Shaikh, B. T., Kahloon, A., Kazmi, M., Khalid, H., Nawaz, K., Khan, N., \& Khan, S. (2004). Students, stress and coping strategies: a case of Pakistani medical school. Education for health-abingdon-carfax publishing limited-, 17, 346-353.

Sherina, M. S., Rampal, L., \& Kaneson, N. (2004). Psychological stress among undergraduate medical students. Medical Journal of Malaysia, 59(2), 207-211.

Sohail, N. (2013). Stress and academic performance among medical students. J Coll Physicians Surg Pak, 23(1), 67-71.

Song, Y., \& Lindquist, R. (2015). Effects of mindfulnessbased stress reduction on depression, anxiety, stress and mindfulness in Korean Nursing Students. Nurse Education Today, 35(1), 86-90.

Supe, A. N. (1998). A study of stress in medical students at Seth GS Medical College.Journal of postgraduate medicine, 44, (1), 1.

Tang, F., Byrne, M., \& Qin, P. (2018). Psychological distress and risk for suicidal behavior among university students in contemporary China. Journal of affective disorders, 228, 101-108.

Trautmann, S., Rehm, J., \& Wittchen, H. U. (2016). The economic costs of mental disorders: Do our societies react appropriately to the burden of mental disorders? EMBO reports, 17(9), 1245-1249.

Uehara, T., Takeuchi, K., Kubota, F., Oshima, K., \& Ishikawa, O. (2010). Annual transition of major depressive episode in university students using a structured self-rating questionnaire. Asia-Pacific Psychiatry, 2(2), 99-104.

Urquijo, I., Extremera, N., \& Villa, A. (2016). Emotional intelligence, life satisfaction, and psychological 
well-being in graduates: the mediating effect of perceived stress. Applied Research in Quality of Life, 11(4), 1241-1252.

Van der Riet, P., Rossiter, R., Kirby, D., Dluzewska, T., \& Harmon, C. (2015). Piloting a stress management and mindfulness program for undergraduate nursing students: Student feedback and lessons learned. Nurse Education , 35(1), 44-49.

World Health Organization (WHO). (2017). Mental health: suicide data. Retrieved from: http://www. who.int/mental_health/prevention/suicide/ suicideprevent/en/

Wu, D., Rockett, I. R., Yang, T., Feng, X., Jiang, S., \&\& Yu, L. (2016). Deliberate self-harm among Chinese medical students: a population-based study. Journal of affective disorders, 202, 137-144.

Wyatt, T., \& Oswalt, S. B. (2013). Comparing mental health issues among undergraduate and graduate students. American Journal of Health Education, 44(2), 96-107.

Zimmaro, L. A., Salmon, P., Naidu, H., Rowe, J., Phillips, K., Rebholz, W. N., \& ... Jablonski, M. E. (2016). Association of dispositional mindfulness with stress, cortisol, and well-being among university undergraduate students. Mindfulness, 7(4), 874885. 